\title{
Single-stage versus 2-stage repair of coarctation of the aorta with ventricular septal defect
}

\author{
Henry L. Walters, III, MD, Constantine E. Ionan, MD, Ronald L. Thomas, PhD, and Ralph E. Delius, MD
}

Earn CME credits at http:// cme.ctsnetjournals.org
Objective: The results of single-stage and 2-stage repair of coarctation of the aorta with ventricular septal defect have improved, but the optimal treatment strategy remains controversial. This study compares our results with these 2 approaches.

Methods: We performed a retrospective analysis of 46 patients, 23 with single-stage repair and 23 with 2-stage repair, who underwent completed surgical treatment of coarctation of the aorta with a ventricular septal defect at the Children's Hospital of Michigan between March 1994 and June 2006.

Results: The average number of operations in the single-stage group was $1.5 \pm 0.6$, and in the 2 -stage group it was $2.2 \pm 0.4(P \leq .0001)$. Postoperative complications were similar, except for the number of planned reoperations to perform delayed sternal closure in the single-stage operation $(\mathrm{n}=7)$ compared with the 2 -stage operation ( $\mathrm{n}=1, P=.023$ ). The patient age in the single-stage group at the time of discharge (completed repair time) was a median of 39.0 days (range, 19-250 days) compared with a median of 113.0 days (range, 26-1614 days) in the 2-stage group after stage $2(P \leq .0001)$. Freedom from cardiac reintervention was $89.8 \%$ in the single-stage group versus $84.9 \%$ in the 2 -stage group $(P=.33)$. The hospital mortality was $4.4 \%$ (1 patient) in each group. The actuarial survival rate was $95.7 \%$ in the singlestage group versus $90.6 \%$ in the 2 -stage group $(P=.38)$.

Conclusions: The advantages of single-stage over 2-stage repair of a ventricular septal defect with coarctation of the aorta include an earlier age at completion of repair, fewer operations, and fewer incisions. Postoperative complications and hospital mortality are similar. The one disadvantage of a single-stage repair was the increased need for delayed sternal closure compared with the 2-stage approach.

$\mathrm{T}$ The optimal surgical strategy for the repair of coarctation of the aorta (CoA) associated with a ventricular septal defect (VSD) is controversial. This study was undertaken to compare the results of the single-stage versus the 2-stage methods in a group of patients with CoA-VSD who eventually underwent complete repair of both the CoA and the VSD.

\section{Materials and Methods \\ Data Collection}

The medical records of 63 consecutive neonates and infants, all less than 6 months of age, who presented with CoA-VSD from March 1994 through June 2006, were retrospectively reviewed after obtaining institutional review board approval with waiver of consent. Of the original group of 63 patients, $46(73 \%)$ underwent complete repair of both the CoA and the VSD. Twenty-three patients (group I-S) underwent a single-stage complete repair of the CoA-VSD, and the remaining 23 patients (group II-S) underwent complete repair with the 2 -stage approach. The remaining $17(27 \%)$ of the original 63 patients were excluded from the analysis because the VSD spontaneously closed or became clinically insignificant after repair of the CoA alone. Sixteen (94.1\%) of the 17 excluded patients were well compensated physiologically and had small VSDs (7 perimembranous and 9 muscular). None of these 16 patients required pulmonary artery (PA) banding. Only 1 (5.9\%) patient in this excluded group had a small- to moderate-sized VSD and underwent PA banding at the time of the coarctation repair. 


$$
\begin{aligned}
& \text { Abbreviations and Acronyms } \\
& \begin{aligned}
\mathrm{ACP} & =\text { antegrade cerebral perfusion } \\
\mathrm{CoA} & =\text { coarctation of the aorta } \\
\mathrm{CPB} & =\text { cardiopulmonary artery } \\
\mathrm{DHCA} & =\text { deep hypothermic total circulatory arrest } \\
\mathrm{DSC} & =\text { delayed sternal closure } \\
\mathrm{PA} & =\text { pulmonary artery } \\
\text { PDA } & =\text { patent ductus arteriosus } \\
\text { VSD } & =\text { ventricular septal defect }
\end{aligned}
\end{aligned}
$$

\section{Analysis}

Quantitative variables that approximated a normal distribution were reported as the mean \pm SD and were analyzed by using the Student unpaired $t$ test. Quantitative variables that did not approximate a normal distribution were reported as the median with a range and were analyzed by using the nonparametric Mann-Whitney rank sum test. Categorical data were analyzed by using the Fisher exact test. Survival and reintervention rates were estimated by using the Kaplan-Meier method.

\section{Demographics}

There were $9(39 \%)$ girls and $14(61 \%)$ boys in group I-S compared with $13(57 \%)$ girls and $10(43 \%)$ boys in group II-S $(P=.118)$. The median ages of the patients at the time of first surgical intervention were 14 days (range, 4-162 days) and 9 days (range, 1-138 days), respectively, for groups I-S and II-S $(P=.109)$. The median age at the time of the second-stage surgical intervention in group II-S was 117 days (range, 16-1611 days). At the time of the first surgical intervention, the mean patient weights in groups I-S and II-S were identical at $3.2 \pm 0.8 \mathrm{~kg}$. The mean weight of the group II-S patients at the time of their second surgical intervention was $5.8 \pm 3.0 \mathrm{~kg}$.

\section{Cardiac Morphologic Characteristics}

The morphologic characteristics of the aortic arch and the VSD, as determined by means of echocardiography with or without cardiac catheterization/cineangiography and confirmed by means of intraoperative observation, are listed in Table 1 . A patent ductus arteriosus (PDA) was present in $15(65 \%)$ of the group I-S patients compared with $17(74 \%)$ of the group II-S patients $(P=.206)$.

\section{Effect of era}

Figure 1 illustrates the effect of era on the distribution of the I-S and II-S procedures, with the II-S approach dominating during the earlier experience. Only 2 II-S procedures were performed in the last 7 years of the study interval compared with $15 \mathrm{I}-\mathrm{S}$ procedures $(P=.027)$.

\section{Group I-S Perfusion Strategy}

The choice of perfusion strategy in the group I-S patients was partially determined by the size of the patient, which influenced the technical feasibility of minimizing deep hypothermic total circulatory arrest (DHCA) by the use of cardiopulmonary bypass (CPB) during all or part of the VSD closure. Later in the series, the use of antegrade cerebral perfusion (ACP) during part of the aortic arch repair further reduced the need for DHCA. Because of individual patient factors, the group I-S perfusion strategies were diverse. They are organized and schematically represented in Figure 2.

\section{Group I-S Surgical Technique (With Antegrade Cerebral Perfusion)}

When possible, percutaneous arterial access was obtained proximal and distal to the coarctation site. Dual arterial cannulation of the descending aorta through the PDA and of the distal ascending aorta or a 3.5- to 4.0-mm polytetrafluoroethylene* tube graft sutured to the innominate artery was performed. The patient was gradually cooled to $18^{\circ} \mathrm{C}$ rectally. A cardioplegic cannula was placed relatively low in the proximal portion of the ascending aorta just distal to the sinotubular junction. The proximal ascending aorta was clamped just distal to the cardioplegic cannula, placing the crossclamp handle inferiorly to avoid interfering with the aortic reconstruction.

Near the completion of the cardioplegic infusion, a period of DHCA was instituted. The PDA was divided, and the aortic isthmus just distal to the origin of the left subclavian artery was suture ligated and divided. The descending thoracic aorta was circumferentially mobilized deep into the chest. ACP was then initiated at 20 to 50 $\mathrm{mL} \cdot \mathrm{kg}^{-1} \cdot \min ^{-1}$ while monitoring the pressure in the right radial arterial line to avoid cerebral arterial hypertension. An end-to-side anastomosis was constructed between the proximal descending thoracic aorta and the distal ascending aorta-transverse arch. The VSD was closed with an interrupted suture technique either partially or completely by using $\mathrm{CPB}$.

\section{Group I-S Surgical Technique (Without Antegrade Cerebral Perfusion)}

Dual arterial cannulae were used, cannulating the descending aorta through the PDA and cannulating the distal, anterolateral ascending aorta near the origin of the innominate artery. The conduct of CPB and aortic mobilization was identical to that described previously. The technique of aortic reconstruction differed only in the fact that it was performed entirely with DHCA. VSD closure was performed as described above.

\section{Group II-S Surgical Strategy and Technique}

The 23 group II-S patients underwent a first-stage repair of the CoA, generally through a left posterolateral thoracotomy incision $(n=20$; $87 \%)$. Three (13\%) underwent their first-stage coarctation repair through a median sternotomy incision by using CPB because of severe proximal aortic arch hypoplasia. Table 2 lists the surgical approaches and techniques used to achieve first-stage repair of the coarctation in the group II-S patients. In the earlier phase of the study period, subclavian flap patch angioplasty, or a variant thereof, was our institutional technique of choice for the repair of CoA and was therefore the most frequently used technique in group II-S.

Seven $(30 \%)$ of the group II-S patients underwent placement of a PA band coincident with the first-stage repair of the CoA to treat severe pulmonary overcirculation present at the time of the coarctation repair. The median interval from first- to second-stage repair in group II-S was 46 (6-1598) days for the patients who did not have a PA band placed and was 178 days (range, 71-321 days) in the patients who did undergo PA banding $(P=.057)$.

Although 17 (74\%) group II-S patients underwent their staged palliation over the course of 2 separate hospital admissions, 6 (26\%) could not be discharged from the hospital and had to undergo both stages during a single hospital admission.

\footnotetext{
* Gore-Tex Vascular Graft, W.L. Gore \& Associates, Inc., Flagstaff, Ariz.
} 
TABLE 1. Cardiac morphologic characteristics of group I-S and group II-S patients with CoA-VSD

\begin{tabular}{lllcrc}
\hline $\begin{array}{c}\text { Cardiac anatomic } \\
\text { structure }\end{array}$ & Morphologic variable & Morphologic descriptor & Group I-S, $\mathbf{n}$ (\%) & Group II-S, $\mathbf{n}$ (\%) & P value \\
\hline Aortic arch & Diameter & Hypoplastic & $19(83 \%)$ & $18(78 \%)$ & .500 \\
Aortic isthmus only & Diameter & Hypoplastic & $4(17 \%)$ & $5(22 \%)$ & .500 \\
VSD $^{*}$ & Size & Large & $20(87 \%)$ & $22(96 \%)$ & .250 \\
& & Moderate & $2(9 \%)$ & $1(4 \%)$ & .500 \\
VSD & Type & Multiple & $1(4 \%)$ & $0(0 \%)$ & .500 \\
& & Perimembranous & $13(17 \%)$ & $2(9 \%)$ & .333 \\
& & Subarterial & $2(9 \%)$ & $13(57 \%)$ & .617 \\
& & Inlet & $1(4 \%)$ & $2(9 \%)$ & .696 \\
& & Muscular & $3(13 \%)$ & $5(4 \%)$ & .756 \\
& & & & $5(22 \%)$ & .350 \\
\hline
\end{tabular}

CoA-VSD, Coarctation of the aorta-ventricular septal defect. *VSD size at the time of the initial surgical intervention.

\section{Results}

\section{Postoperative Complications}

The postoperative surgical complications are listed in Table 3. There were $7(30 \%)$ primary elective open sternum/ planned delayed sternal closures (DSCs) performed in group I-S compared with $1(4 \%)$ performed in group II-S $(P=$ .023). The remaining postoperative complications occurred with similar frequencies in both groups.

\section{Surgical Incisions}

In the 23 group I-S patients, complete surgical reconstruction was achieved through the access provided by 23 median sternotomy incisions. Group II-S patients required 43 incisions to achieve complete repair $(P<.0001)$. Three $(13 \%)$ of the group II-S patients had their initial surgical procedure (coarctation repair) performed through a median sternotomy incision. Their subsequent VSD closure was therefore performed through a reoperative median sternotomy incision.

\section{Surgical Procedures}

To accurately assess the true effect of the number of operations required in each group to achieve complete repair, we also included operations to treat complications. Examples included DSC, thoracic duct ligation, diaphragm plication, drainage of pericardial effusion, mediastinal explorations for bleeding, and extracorporeal membrane oxygenation cannulation. There were a mean of $1.5 \pm 0.6$ operations in group I-S and $2.2 \pm 0.4$ operations in group II-S $(P<.0001)$.

\section{Operative Mortality}

The definition of operative mortality applied to this study was identical to that established by the Society of Thoracic Surgeons Congenital Heart Surgery Database. ${ }^{1}$ One (4\%) patient died in each group. The patient who died in group I-S was premature with Jacobsen's syndrome, hyaline membrane disease, pulmonary hypertension, hypoplasia of the left ventricle, and polysplenia. This patient had a sudden and unexplained cardiac arrest after extubation on postoperative day

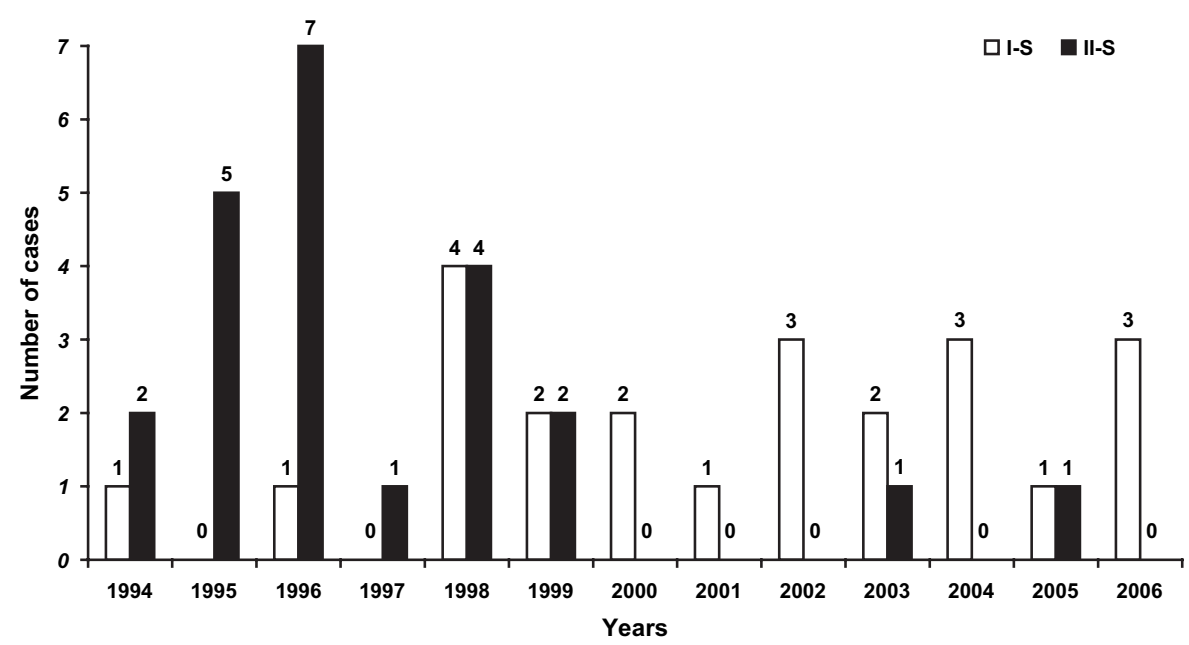

Figure 1. Distribution of group I-S and group II-S repairs over time. 


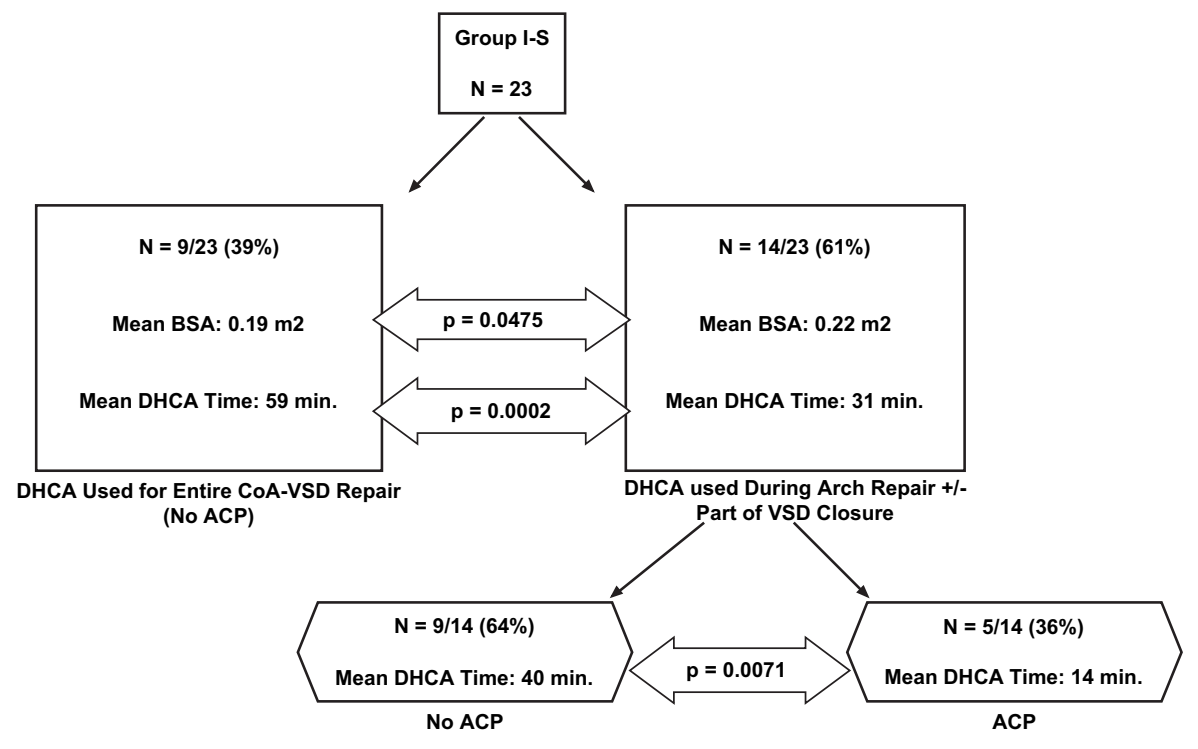

Figure 2. Group I-S perfusion strategy. $B S A$, Body surface area; DHCA, deep hypothermic circulatory arrest; $C o A$, coarctation of the aorta; VSD, ventricular septal defect; $A C P$, antegrade cerebral perfusion.

6. The patient who died in group II-S underwent an initial repair of coarctation with placement of a PA band for Swiss-cheese septum. After the second-stage PA debanding and repair of multiple VSDs, the patient had low cardiac output and multiorgan failure. He died on postoperative day 5 despite extracorporeal membrane oxygenation support.

\section{Cumulative Days in the Hospital}

The cumulative hospital days to completed repair for the 22 group I-S and 22 group II-S survivors was defined as the total

TABLE 2. Group II-S coarctation surgical repair techniques and incisions

\begin{tabular}{|c|c|c|}
\hline \multirow[b]{2}{*}{ Coarctation repair technique } & Incision & \multirow[b]{2}{*}{$\begin{array}{c}\text { Median sternotomy, } \\
\text { n (\%) }\end{array}$} \\
\hline & $\begin{array}{l}\text { Left thoracotomy, } \\
\text { n (\%) }\end{array}$ & \\
\hline Forward subclavian flap & $12(52 \%)$ & \\
\hline $\begin{array}{l}\text { End-to-end }+ \text { reverse } \\
\text { subclavian flap }\end{array}$ & $3(13 \%)$ & \\
\hline $\begin{array}{l}\text { End-to-end }+ \text { forward } \\
\text { subclavian flap }\end{array}$ & $2(9 \%)$ & \\
\hline Reverse subclavian flap & $1(4 \%)$ & \\
\hline $\begin{array}{l}\text { Subclavian flap }+ \text { patch } \\
\text { angioplasty of aortic arch }\end{array}$ & $1(4 \%)$ & \\
\hline $\begin{array}{l}\text { Patch angioplasty } \\
\text { of aortic arch }\end{array}$ & $1(4 \%)$ & \\
\hline $\begin{array}{l}\text { Extended end-to-side } \\
\text { anastomosis }\end{array}$ & & $2(9 \%)$ \\
\hline $\begin{array}{l}\text { Allograft augmentation } \\
\text { of aortic arch }\end{array}$ & & $1(4 \%)$ \\
\hline Total & $20(87 \%)$ & $3(13 \%)$ \\
\hline
\end{tabular}

number of hospital days for each patient from the day of the index operation (group I-S) or operations (group II-S) to the day of hospital discharge. The median number of cumulative hospital days for group I-S was 23 (range, 5-248 days), and the median number of days was 25 (range, 12-83 days) for group II-S $(P=.510)$.

\section{Age at Completed Repair}

The age at completed repair was defined as the age of the 22 group I-S and 22 group II-S survivors at which they

\section{TABLE 3. Postoperative complications}

\begin{tabular}{lccc}
\hline \multicolumn{1}{c}{ Complication } & Group I-S, & Group II-S, & \\
& $\mathbf{n}(\%)$ & $\mathbf{n}(\%)$ & $\boldsymbol{P}$ value \\
\hline Diaphragm paralysis (plication) & $1(4 \%)$ & $1(4 \%)$ & .756 \\
Vocal cord paralysis/paresis & $1(4 \%)$ & $1(4 \%)$ & .756 \\
Pneumothorax requiring & $1(4 \%)$ & $1(4 \%)$ & .756 \\
$\quad$ tube thoracostomy & & & \\
Chylothorax requiring intervention & $1(4 \%)$ & $1(4 \%)$ & .756 \\
Pericardial effusion requiring & $2(9 \%)$ & $2(9 \%)$ & .696 \\
$\quad$ drainage & & & \\
Arrhythmia (junctional ectopic & $1(4 \%)$ & $1(4 \%)$ & .756 \\
$\quad$ tachycardia) & & & \\
Mediastinal exploration & $1(4 \%)$ & $0(0 \%)$ & .500 \\
$\quad$ for hemorrhage & $7(30 \%)$ & $1(4 \%)$ & .023 \\
PEOS/DSC & $1(4 \%)$ & $1(4 \%)$ & .756 \\
Low cardiac output requiring ECMO & $0(0 \%)$ & $1(4 \%)$ & .500 \\
Multiorgan failure & $1(4 \%)$ & $1(4 \%)$ & .756 \\
Necrotizing enterocolitis & $0(0 \%)$ & $1(4 \%)$ & .500 \\
Seizures (new onset) &
\end{tabular}

PEOS, Primary elective open sternum; DSC, delayed sternal closure; ECMO, extracorporeal membrane oxygenation. 


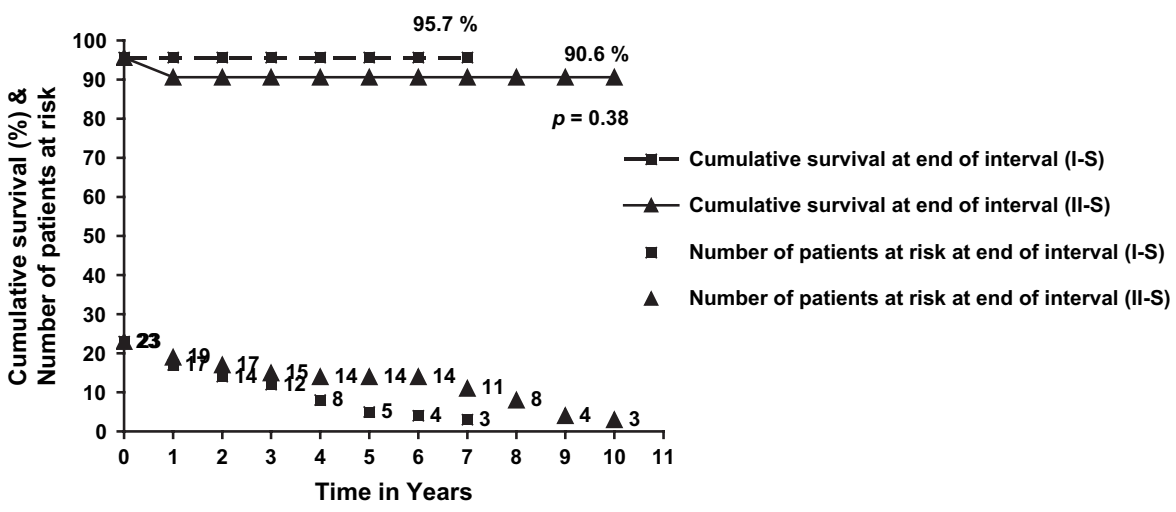

Figure 3. Actuarial survival of group I-S and group II-S patients.

completed their entire surgical reconstruction and were hence restored to a normal cardiac anatomy and physiology. In group I-S the median age at completed repair was 39 days (range, 19-250 days), whereas it was 113 days (range, 261614 days) in group II-S $(P<.0001)$.

\section{Follow-up}

The mean length of follow-up for group I-S was $3.3 \pm 2.7$ years, and for group II-S, it was $6.3 \pm 3.7$ years $(P=$ .0027). There was 1 late death in group II-S. The actuarial survival for the 2 groups was similar $(95.7 \%$ for group I-S vs $90.6 \%$ for group II-S, $P=.38$ ) and is depicted in Figure 3.

\section{Cardiac Reintervention}

Cardiac reinterventions were defined as surgical or catheterbased procedures that involved the heart, great vessels, or both, regardless of whether these procedures seemed directly related to the surgical treatment of the CoA-VSD (Table 4). The freedom from all types of cardiac reintervention was $89.8 \%$ in group I-S and $84.9 \%$ in group II-S $(P=.33$, Figure 4). Two patients in each group are being followed for mild follow-up peak echocardiographic gradients without any clinical signs (arm-leg gradients), symptoms, or evidence of left ventricular hypertrophy, dysfunction, or both.

\section{Discussion}

\section{Study Purpose}

The decision-making process for the surgical management of CoA-VSD is controversial ${ }^{2}$ because the ability to predict spontaneous closure or significant regression of the VSD is imperfect, the determination of clinically significant proximal aortic arch hypoplasia is often subjective, and little is known about the comparative advantages of the single-stage versus the 2-stage approaches. The purpose of this study was to define the benefits and liabilities of the single-stage versus the 2-stage approach for the repair of CoA with a moderateto-large VSD in symptomatic neonates and young infants who undergo repair of both the CoA and the VSD.

\section{Aortic Arch Anatomy}

Important transverse aortic arch hypoplasia coexists in as many as $65 \%$ of neonatal patients with $\mathrm{CoA}$ in recent series. ${ }^{2-4}$ Associated intracardiac defects, such as VSD and various forms of left ventricular outflow tract obstruction, probably result in an even higher incidence of associated aortic arch hypoplasia. This assertion is supported by the hemodynamic flow theory that postulates a paucity of aortic blood flow during fetal development as a causative agent for the development of $\mathrm{CoA}$ and the frequently associated aortic arch hypoplasia. ${ }^{4-11}$ Our data corroborate the literature in that approximately $80 \%$ of both the group I-S and group II-S patients had aortic arch hypoplasia proximal to the aortic isthmus.

\section{Principles and Problems in Surgical Decision Making}

The decision-making process for determining the optimal surgical strategy to address the neonate and infant with CoA-VSD includes a detailed knowledge of the patient's clinical condition, the anatomy of the entire aortic arch, and the identification of all important associated intracardiac defects. This pertinent anatomic information can usually be provided by means of echocardiographic analysis alone. Rarely is it necessary to supplement echocardiographic data with cardiac catheterization/cineangiography, computerized cross-sectional imaging, or both. Also pertinent to surgical decision making is the observation that when all patients, regardless of the size of the VSD, who present during a given time interval with CoA-VSD are analyzed, a significant percentage will experience spontaneous closure of perimembranous and muscular VSDs after repair of the CoA alone with or without PA banding. Posterior malalignment and subarterial VSDs will never close, and large perimembranous VSDs, especially those with inlet extension, outlet extension, or both, will rarely close spontaneously. In the series of Brouwer and colleagues, ${ }^{2}$ for example, $58 \%$ of all patients who underwent CoA repair with or without PA banding experienced spontaneous closure of the VSD compared with 
TABLE 4. Cardiac reinterventions (surgical/catheter)

\begin{tabular}{lccc}
\hline \multicolumn{1}{c}{ Reintervention site (type) } & Group I-S, $\mathbf{n}$ & Group II-S, $\mathbf{n}$ & $\boldsymbol{P}$ value \\
\hline Cardiac (surgical) & $1^{*}$ & $1 \dagger$ & .511 \\
Aortic arch (surgical) & $1 \ddagger$ & $2 \ddagger$ & .383 \\
Aortic valve (catheter) & $1 \S$ & $1 \S$ & .511 \\
Total no. of patients & $2 \|$ & $3 \rrbracket$ & .327 \\
Total no. of reinterventions & $2 \|$ & 4 & .239 \\
\hline
\end{tabular}

${ }^{*}$ Closure residual ventricular septal defect. $†$ Systemic-to-pulmonary artery shunt 6 months after pulmonary artery banding to temporize during regression of mediastinal hemangioma. $\ddagger$ Patch aortoplasty of proximal aortic arch. $\S$ Aortic valve percutaneous balloon dilation. ॥One patient underwent 1 reintervention at 2 different sites. $\lceil 0$ ne patient underwent 2 reinterventions at 2 different sites.

$17(43 \%)$ of 40 in the present series. Although hemodynamic $^{2}$ and morphologic ${ }^{2}$ predictors of which VSDs are likely to close spontaneously have been proposed, our knowledge of this aspect of the natural history of CoAVSD remains imperfect. Furthermore, accurate measurements of VSD and left ventricular outflow tract gradients, as well as shunts, are confounded by the frequent presence of a large PDA and by the aortic arch obstruction itself.

The proximal extent of clinically significant aortic arch hypoplasia will also have an important effect on the choice of surgical strategy because resection with extended endto-end anastomosis repair of CoA through a left thoracotomy incision cannot always address arch hypoplasia that is proximal to the left common carotid artery. Similarly, the presence of proximal arch hypoplasia in conjunction with a common trunk for the right-sided innominate artery and the left common carotid artery can present technical difficulties for coarctation repair through a left thoracotomy incision.

\section{Categorization of Surgical Strategies}

Three broad surgical strategies for the repair of patients who present with CoA-VSD are described in the literature. We have elected to categorize these as (1) complete single-stage repair with either 1 or 2 incisions, (2) committed 2-stage repair, and (3) uncommitted 2-stage repair.

The complete single-stage strategy is the most complex and comprehensive. It involves repairing both the coarctation and the VSD in one operation, usually through a single median sternotomy incision and always using CPB with or without DHCA with or without ACP with or without isolated myocardial perfusion. ${ }^{2,12-17}$ Kanter and associates ${ }^{18}$ have also reported a single-stage technique for repair of CoAVSD (without clinically significant proximal aortic arch hypoplasia) that involves the use of a left thoracotomy incision for the coarctation repair, followed by an immediate median sternotomy incision for repair of the VSD. This technique obviates the use of DHCA and $\mathrm{ACP}$ and results in shorter $\mathrm{CPB}$ times. The committed 2-stage approach is "committed" to the use of at least 2 operations (and usually 2 incisions) and is somewhat less complex than the single-stage approach. It consists of coarctation repair with PA banding (usually through a left thoracotomy incision without CPB), followed by interval PA debanding with or without VSD closure through a median sternotomy incision using CPB. ${ }^{19}$ The uncommitted 2-stage strategy is the most optimistic of these 3 surgical categories for the repair of CoA-VSD in that it relies heavily for its optimal outcome on the tendency for some VSDs to close spontaneously. This approach is therefore not always "committed" to the performance of 2 surgical procedures but involves cooperation with nature to accomplish the complete (or near-complete) restoration of normal anatomy and physiology. The uncommitted 2-stage strategy can be divided into 2 types. Type I consists of coarctation repair alone (usually through a left thoracotomy incision without $\mathrm{CPB}$ ) and expectant management of the VSD. Interval closure of the VSD, through a median sternotomy incision with CPB, is later performed only if the patient still has a clinically significant VSD. ${ }^{20}$ Type II has only been reported once and consists of coarctation repair with PA banding using an absorbable banding material, followed by interval VSD closure, if necessary. ${ }^{21}$

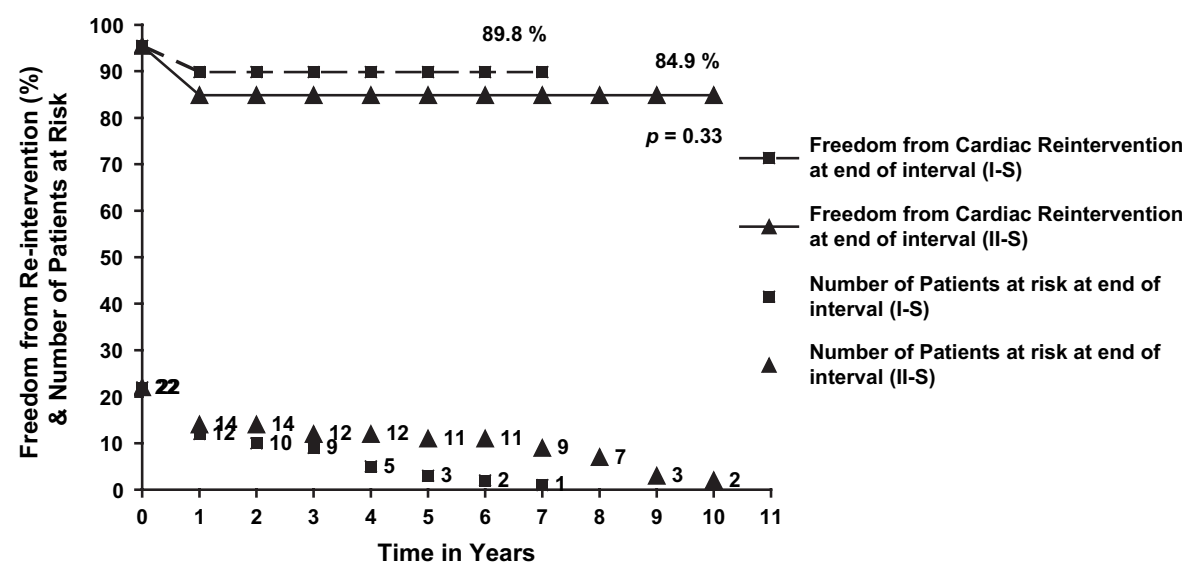

Figure 4. Freedom from cardiac reintervention in group I-S and group II-S patients. 


\section{CoA-VSD With a Restrictive VSD}

With this background, a reasonable and relatively noncontroversial approach in well-compensated patients with CoA and an unequivocally small, restrictive, and clinically insignificant perimembranous or muscular VSD is a type I uncommitted 2-stage strategy consisting of repair of the CoA alone through a left thoracotomy incision, followed by expectant management of the VSD. ${ }^{2,20}$ In this situation there is usually no compelling reason to consider simultaneous repair of the VSD or placement of a PA band. One exception to this generalization is the coexistence of severe, proximal aortic arch hypoplasia that cannot be adequately addressed through a left thoracotomy incision and requires repair with CPB through a median sternotomy incision. ${ }^{15}$ In this case simultaneous closure of the VSD in a single stage might be expedient given the necessity of using CPB for the CoA repair.

\section{CoA-VSD With a Moderate-to-large VSD}

Conversely, the decision-making process for the surgical management of CoA with a moderate-to-large VSD is more difficult and controversial. ${ }^{2}$ Critics of the single-stage approach cite as possible liabilities of this technique (1) an increased morbidity and mortality risk associated with the more complex single-stage cardiac surgery, (2) possible complications associated with DHCA/ACP and the allogeneic blood transfusions that are intrinsic to the single-stage strategy, and (3) an increased potential for recoarctation. ${ }^{2}$ Another legitimate criticism includes (1) the lack of evidence in clinical studies for the protective effect of ACP in ameliorating the detrimental neurodevelopmental effects of $\mathrm{DHCA}^{22}$ and (2) the relatively long hospital stay in our experience associated with this technique, which might relate to the need for prolonged postoperative efforts to establish effective nippling patterns. Alternatively, the practical advantages of single-stage repair include (1) immediate restoration of normal anatomy and physiology; (2) the ability to definitively correct the entire range of commonly associated transverse aortic arch hypoplasia; (3) the avoidance of possible complications associated with PA banding, including PA distortion and right ventricular hypertrophy ${ }^{23}$; (4) avoidance of the possible future development of scoliosis and restrictive pulmonary function in infants with both a lateral thoracotomy and a median sternotomy incision; (5) avoidance of interval congestive heart failure and the possible need for medical therapy or urgent and unplanned surgical intervention (if PA banding is not performed); and (6) avoidance of the development of double-chambered right ventricle, membranous subaortic obstruction, and/or aortic valve dysfunction, all of which can sometimes accompany spontaneous complete or incomplete VSD closure. In our analysis we were able to establish that the single-stage approach, although complex, was not associated with an increased mortality compared with the 2-stage strategy. The morbidity of the 2 techniques was comparable except for the increased need for primary elective open sternum and planned DSC, a liability that has, in recent years, been neutralized in our practice, probably because of the development of better techniques for CPB and myocardial protection, as well as the routine use of postbypass modified ultrafiltration. The single-stage group achieved an anatomic and physiologic correction at a younger age, with fewer incisions and fewer operations. Restoring normalcy at a younger age should not be underestimated because it is known that in addition to intraoperative variables, there are yet to be identified prenatal, postnatal, preoperative, and postoperative variables that contribute significantly to neurodevelopmental outcomes. ${ }^{24}$ The total number of hospital days, the freedom from cardiac reintervention, and the postdischarge survival were not different between the 2 groups.

Advocates of the committed and uncommitted 2-stage strategy, in this clinical situation, can claim as its advantages (1) diffusion of surgical complexity, (2) the unlikely requirement for DHCA, and (3) the possibility of spontaneous closure of the VSD, thus obviating the need for VSD closure (although PA debanding with or without PA angioplasty might still be required). It should be noted, though, that $26 \%$ of our uncommitted group II-S patients were not able to be discharged because of refractory congestive heart failure and had to undergo an unplanned second operation during their original hospitalization.

\section{Rationale for the Study Design}

We did not attempt to define morphologic or hemodynamic predictors of spontaneous VSD closure in neonates and young infants with CoA-VSD. For this reason, the 17 patients who experienced spontaneous VSD closure or clinically important regression after repair of CoA were not included in our analysis. This exclusion left 2 relatively homogeneous groups of patients for testing the hypothesis that there are important clinical advantages to the single-stage complete repair of neonatal/infant CoA-VSD compared with the 2-stage approach when both the CoA and the VSD are repaired. In this sense our study design was similar to that of Ishino and coworkers. ${ }^{14}$ The results of this type of analysis of the surgical repair of CoA-VSD will grow in importance as more is learned, over time, about precise predictors of spontaneous VSD closure/regression and about markers of clinically significant proximal aortic arch hypoplasia.

\section{Study Limitations}

One limitation of this study relates to its retrospective design, resulting in a lack of fixed criteria for consistent assignment of individual patients to one of the 2 study groups. Also, although the study groups were comparable in terms of demographics, cardiac morphology, and clinical presentation, there was a definite effect of era on the distribution of the surgical approaches. Finally, the follow-up in group I-S was relatively short. 


\section{Conclusions}

Single-stage complete repair of neonatal/infant CoA-VSD confers important advantages to patients who need to undergo repair of both the CoA and the VSD when compared with the 2-stage approach. Suggested strategies for application of the single-stage and 2-stage repairs are provided. The future determination of more precise predictors of spontaneous VSD closure or important VSD regression and a better understanding of what defines clinically significant proximal aortic arch hypoplasia will further improve the decision-making process in the surgical treatment of this complex group of patients.

\section{References}

1. Jacobs JP, Mavroudis C, Jacobs ML, Maruszewski B, Tchervenkov CT, Lacour-Gayet FG, et al. What is operative mortality? Defining death in a surgical registry database: a report of the STS Congenital Database Taskforce and the Joint EACTS-STS Congenital Database Committee. Ann Thorac Surg. 2006;81:1937-41.

2. Brouwer RMHJ, Cromme-Kijkhuis AH, Erasmus ME, Contant C, Bogers AJJC, Elzenga NJ, et al. Decision making for the surgical management of aortic coarctation associated with ventricular septal defect. J Thorac Cardiovasc Surg. 1996;111:168-75.

3. Vouhe PR, Trinquet F, Lecompte Y, Vernant F, Roux PM, Touati G, et al. Aortic coarctation with hypoplastic aortic arch. Results of extended end-to-end aortic arch anastomosis. J Thorac Cardiovasc Surg. 1988;96: 557-63.

4. Lacour-Gayet F, Bruniaux J, Derraf S, Chambran P, Blaysat G, Losay J, et al. Hypoplastic transverse arch and coarctation in neonates. Surgical reconstruction of the aortic arch: a study of sixty-six patients. $J$ Thorac Cardiovasc Surg. 1990;100:808-16.

5. Rudolph AM, Heymann JA, Spitznas U. Hemodynamic consideration in the development of narrowing of the aorta. Am J Cardiol. 1972;30: 514-25.

6. Anderson RH, Lenox CC, Zuberbuhler JR. Morphology of ventricular septal defect associated with coarctation of aorta. Br Heart J. 1983;50: 176-81.

7. Olley PM, Coceani F, Bodach E. E-type prostaglandins: a new emergency therapy for certain cyanotic congenital heart malformations. Circulation. 1976;53:728-31.

8. Bharati S, Lev M. The surgical anatomy of the heart in tubular hypoplasia of the transverse aorta (preductal coarctation). J Thorac Cardiovasc Surg. 1986;91:79-85.

9. Moulaert AJ, Bruins CC, Oppenheimer-Dekker A. Anomalies of the aortic arch and ventricular septal defects. Circulation. 1976;53:1011-5.
10. Ho SY, Anderson RH. Coarctation, tubular hypoplasia, and the ductus arteriosus: histological study of 35 specimens. Br Heart J. 1979;41: 268-74.

11. Becker AE, Becker J, Edwards JE. Anomalies associated with coarctation of the aorta: particular reference to infancy. Circulation. 1970;41: 1067-75.

12. Gaynor JW, Wernovsky G, Rychik J, Rome JJ, DeCampli WM, Spray TL. Outcome following single-stage repair of coarctation with ventricular septal defect. Eur J Cardiothorac Surg. 2000;18:62-7.

13. Gaynor JW. Management strategies for infants with coarctation and an associated ventricular septal defect. J Thorac Cardiovasc Surg. 2001; 122:424-6.

14. Ishino K, Kawada M, Irie H, Kino K, Sano S. Single-stage repair of aortic coarctation with ventricular septal defect using isolated cerebral and myocardial perfusion. Eur J Cardiothorac Surg. 2000;17:538-42.

15. Elgamal MA, McKenzie ED, Fraser CD. Aortic arch advancement: the optimal one-stage approach for surgical management of neonatal coarctation with arch hypoplasia. Ann Thorac Surg. 2002;73:1267-73.

16. Sandhu SK, Beekman RH, Mosca RS, Bove EL. Single-stage repair of aortic arch obstruction and associated intracardiac defects in the neonate. Am J Cardiol. 1995;75:370-3.

17. Quaegebeur JM, Jona RA, Weinberg AD, Blackstone EH, Kirklin JW. Outcomes in seriously ill neonates with coarctation of the aorta: a multiinstitutional study. J Thorac Cardiovasc Surg. 1994;108:841-54.

18. Kanter KR, Mahle WT, Kogon BE, Kirshbom PM. What is the optimal management of infants with coarctation and ventricular septal defect? Ann Thorac Surg. 2007;84:612-8.

19. Isomatsu Y, Imai Y, Shin'oka T, Aoki M, Sato K. Coarctation of the aorta and ventricular septal defect: should we perform a single-stage repair? J Thorac Cardiovasc Surg. 2001;122:524-8.

20. Conte S, Lacour-Gayet F, Serraf A, Sousa-Uva M, Bruniaux J, Touchot A, et al. Surgical management of neonatal coarctation. J Thorac Cardiovasc Surg. 1995;109:663-75.

21. Bonnet D, Patkai J, Tamisier D, Kachaner J, Vouhé P, Sidi D. A new strategy for the surgical treatment of aortic coarctation associated with ventricular septal defect in infants using an a absorbable pulmonary artery band. J Am Coll Cardiol. 1999;34:866-70.

22. Visconti KJ, Rimmer D, Gauvreau K, del Nido P, Mayer JE, Hagino I, et al. Regional low-flow perfusion versus circulatory arrest in neonates: one-year neurodevelopmental outcome. Ann Thorac Surg. 2006;82: 2207-11.

23. Piluiko VV, Poynter JA, Nemeh H, Thomas RL, Forbes TJ, Delius RE, et al. Efficacy of intraluminal pulmonary artery banding. J Thorac Cardiovasc Surg. 2005;129:544-50.

24. Gaynor JW, Wernovsky G, Jarvik GP, Bernbaum J, Gerdes M, Zackai E, et al. Patient characteristics are important determinants of neurodevelopmental outcome at one year of age after neonatal and infant cardiac surgery. J Thorac Cardiovasc Surg. 2007;133:1344-53. 